\title{
Strategic Planning: Best Practices for Canadian Health Leaders
}

By Dr. John H. Hylton, CHA Press, Ottawa, Ontario Reviewed by Joseph Mapa and Jennifer Snider
Strategic Planning: Best Practices for Canadian Health Leaders, Dr. John Hylton has written a practical handbook for current and aspiring Canadian healthcare leaders. His extensive experience from a variety of positions within both the Canadian and American health systems positions Dr. Hylton well to discuss approaches to strategic planning.

Although strategic planning is not a new or unique concept, a book on this topic is timely given the current flux within the Canadian healthcare environment. The introduction of regionalization, Local Health Integration Networks, integration and accountability has forced many healthcare leaders to critically and strategically review their organizations and the role that they play within the broader healthcare system. Market sensing is vital, but of equal importance is market positioning.

Dr. Hylton presents his readers with a case illustrating why strategic planning should be at the forefront of organizational management. He discusses the growth of the health system, the diverse and intricate nature of planning mandates, the increased expectation for transparency and accountability and the repertoire of new planning concepts and techniques focused on implementation and monitoring that have emerged over the past decade. Importantly, Hylton also addresses the impact of these drivers on strategic planning.

The reader is presented with an overview of the contemporary roots of planning theory and practice. Using approaches from both the health system and private sector, Hylton continues to present a comprehensive review of strategic planning best practices, including scenario planning and appreciative inquiry models. Recognizing that health leaders are seeking to achieve efficiencies and to improve organizational performance, private sector methodologies, including Motorola’s Six Sigma, General Electric's Key Performance Indicators/Dashboards and Kaplan and Norton's Balanced Scorecard, are showcased with the intent of adapting these approaches for use in the health system.

Hylton takes his readers through the steps that are involved in the development and implementation of strategic plans and analyzes the tools and techniques that are available to mitigate the common challenges that are often involved in the strategic planning process. Most importantly, Hylton articulates to his readers the necessity for strategic plans to be relevant and properly aligned with organizational circumstances, goals and objectives.

This book concludes with a constructive guide and checklist that summarize the best practices discussed throughout the book. Health leaders embarking on a strategic planning journey can easily refer to this resource to help direct and shape their organizational planning processes.

Strategic Planning: Best Practices for Canadian Health Leaders is a good read for healthcare executives at the middle and senior management levels and for planners who are interested in refreshing their strategic planning competencies and leading their organizations in a way that is not only strategic but also relevant to the current healthcare landscape. HQ

\section{About the Reviewers}

Joseph Mapa is president and chief executive officer of Mount Sinai Hospital, Toronto, Ontario.

Jennifer Snider is a healthcare consultant at Mount Sinai Hospital. 